\title{
Effect of sodium bicarbonate ingestion during 6 weeks of HIIT on anaerobic performance of college students
}

\author{
Jieting Wang ${ }^{1}$, Junqiang Qiu ${ }^{1 *}$, Longyan $\mathrm{Yi}^{1}$, Zhaoran Hou', Dan Benardot ${ }^{2,3}$ and Wei Cao ${ }^{1}$
}

\begin{abstract}
Background: Past studies have found that sodium bicarbonate ingestion prior to exercise has a performanceenhancing effect on high-intensity exercise. The aim of this study was to investigate the effects of continuous sodium bicarbonate $\left(\mathrm{NaHCO}_{3}\right)$ supplementation on anaerobic performance during six weeks of high-intensity interval training (HIIT).
\end{abstract}

Methods: Twenty healthy college-age male participants were randomly assigned to either the $\mathrm{HCO}_{3}{ }^{-}$group (SB) or the placebo group (PL), with 10 subjects in each group. Both groups completed 6 weeks (3 days/week) of HIIT with the SB ingesting an orange-flavored solution containing $15 \mathrm{~g}$ xylitol and $0.2 \mathrm{~g} \mathrm{HCO}_{3}^{-} / \mathrm{kg}$ body mass during each training day, and $\mathrm{PL}$ ingesting a similar beverage that was $\mathrm{HCO}_{3}{ }^{-}$-free. This study separated 6 weeks of training into two stages with different training intensities, with the first 3 weeks at a lower intensity than the second 3 weeks. Blood samples to measure serum $\mathrm{HCO}_{3}{ }^{-}$were obtained 5 min before and 30 min after the following $\mathrm{HIIT}$ training sessions: Week 1, training session 1 ; week 3 , training session 3; week 6 , training session 3 . Three 30 s Wingate tests (WAnT) were conducted before, in the middle, and after the training and the supplementation interventions, with peak power, mean power, and fatigue index obtained during WAnT, and blood lactate and heart rate obtained after WAnT.

Results: Our findings indicate the following: 1) Serum $\mathrm{HCO}_{3}{ }^{-}$level of SB was significantly higher than $\mathrm{PL}(p<0.05)$ both before and after each HIIT; 2) Relative peak power in WAnT was significantly higher in the SB group after 6 weeks $(p<0.01)$; 3 ) Lactate clearance rate and the lactate clearance velocity after 10 min of WAnT were both significantly higher in SB in the post-test $(p<0.01) ; 4)$ Heart rate recovery rate at 10 min after WAnT in both SB and PL after 6 weeks were significantly improved $(p<0.01$ and $p<0.05$, respectively), resulting in no difference between groups on these measures.

Conclusions: These data suggest that supplementation of $\mathrm{HCO}_{3}{ }^{-}$at the level of $0.2 \mathrm{~g} / \mathrm{kg}$ body mass before HIIT training enhances the effect of HIIT on anaerobic performance, and improves the blood lactate clearance rate and the blood lactate clearance velocity following anaerobic exercise.

Keywords: Sodium bicarbonate, High-intensity interval training, Anaerobic performance

\footnotetext{
* Correspondence: qiujq001@sina.com

${ }^{1}$ College of Kinesiology, Beijing Sport University, Beijing, BJ, China

Full list of author information is available at the end of the article
}

(c) The Author(s). 2019 Open Access This article is distributed under the terms of the Creative Commons Attribution 4.0 International License (http://creativecommons.org/licenses/by/4.0/), which permits unrestricted use, distribution, and reproduction in any medium, provided you give appropriate credit to the original author(s) and the source, provide a link to the Creative Commons license, and indicate if changes were made. The Creative Commons Public Domain Dedication waiver (http://creativecommons.org/publicdomain/zero/1.0/) applies to the data made available in this article, unless otherwise stated. 


\section{Introduction}

High-intensity interval training (HIIT) refers to a training protocol involving multiple bouts of high-intensity exercise or all-out sprints that are interspersed with recovery periods [1]. Results of previous studies support the idea that HIIT significantly promotes both aerobic and anaerobic exercise capacity [2-5]. Studies have found that aerobic capacity could be positively influenced by HIIT through an increase in oxidative enzymes [6], higher oxidative enzymes activity [7-9], better oxygen transfer to cells [10], more mitochondria per cell, and better mitochondrial function [10-12]. Tabata et al. (1996) compared the effects of endurance training and HIIT training on anaerobic abilities [2]. In this study, eight sets of $20 \mathrm{~s}$ high-intensity exercise, with $10 \mathrm{~s}$ intervals between each set, for 5 days/week were completed each training day by the HIIT group [2]. After 6-weeks of training, the anaerobic capacity of the HIIT group increased by $28 \%$, while the endurance training experienced no significant change [2]. Although other studies assessing HIIT have used different training methods, training protocols (training equipment, training intensity and time, etc.), and subject groups, most results suggest that HIIT training effectively improves anaerobic capacity [13-16]. Studies have shown that, because of the high intensity and short duration, HIIT is characterized by an energy supply derived primarily from anaerobic metabolism, although it is known that all three energy systems support the exercise in different proportions during different exercise time periods [17-19]. The ability of maintaining the required power output is related to the capacity to continuously supply ATP by anaerobic glycolysis. The benefit of pursuing higher power output in high-intensity exercise alters the kinetics of oxygen uptake $\left(\mathrm{VO}_{2}\right)$, which can also support anaerobic performance by diminishing the demand on relatively limited anaerobic fuel sources. The study of Tomlin et al. (2001) showed a positive relationship between aerobic fitness and power recovery from high intensity intermittent exercise [20]. It appears, therefore, that the improvement in anaerobic capacity during HIIT training is likely from the combined results of enhanced phosphocreatine energy supply capacity [21], improved glycolytic enzyme activity [22, 23], and enhanced aerobic metabolism [20].

While in a state of rest, human blood is slightly alkaline $(\mathrm{pH} \sim 7.4)$, while muscle is neutral $(\mathrm{pH} \sim$ 7.0). Constant mediation of the blood and muscle acid-base balance is one of the important requirements to assure normal cellular metabolism. By neutralizing excess acidity and/or alkalinity, buffering systems in the body attempt to maintain the $\mathrm{pH}$ in a desired/healthy range. A primary buffering system is the carbonic acid $\left(\mathrm{H}_{2} \mathrm{CO}_{3}\right)$-bicarbonate ion
$\left(\mathrm{HCO}_{3}{ }^{-}\right)$system, which functions through the reaction below:

$$
\mathrm{H}^{+}+\mathrm{HCO}_{3}^{-} \leftrightharpoons \mathrm{H}_{2} \mathrm{CO}_{3} \leftrightharpoons \mathrm{H}_{2} \mathrm{O}+\mathrm{CO}_{2}
$$

Studies have confirmed that acidosis negatively impacts the release of calcium ions during muscle contraction, the activation of electrical signal receptors, the binding of calcium ions to troponin $\mathrm{C}$, and metabolic enzyme activity [24-27]. These changes have the effect of hindering ATP re-synthesis and slowing glycolysis. Acidosis can result from a drop in intracellular $\mathrm{pH}$ during short-duration intense anaerobic exercise. Studies have found that $\mathrm{HCO}_{3}{ }^{-}$can buffer the accelerated release of hydrogen ions associated with this intense anaerobic activity, thereby lowering acidosis. In addition, the sodium ion $\left(\mathrm{Na}^{+}\right)$in sodium bicarbonate $\left(\mathrm{HCO}_{3}{ }^{-}\right)$ can be beneficial by neutralizing the acid impact of the hydrogen ion $\left(\mathrm{H}^{+}\right)$. It has also been established that ingestion of $\mathrm{Na}^{+}$can increase the plasma volume [28], which could be an additional benefit to anaerobic activity by creating an enlarged buffering potential through dilution of the $\mathrm{H}^{+}$concentration. Other studies also have found that acute or chronic exogenous $\mathrm{HCO}_{3}{ }^{-}$may improve performance in 400 and $800 \mathrm{~m}$ races, 2 min sprints, the Wingate test, and other anaerobic activities [29-35].

The timing of acute $\mathrm{HCO}_{3}{ }^{-}$supplementation in past studies typically ranges from 1 to $3 \mathrm{~h}$ prior to exercise, which significantly raises the blood $\mathrm{HCO}_{3}{ }^{-}$level and $\mathrm{pH}$ in the blood [36]. Studies have found that the activity of $\mathrm{H}^{+}$transmembrane protein increases in proportion to the rise of intracellular $\mathrm{H}^{+}$concentration [37]. As a result, the $\mathrm{H}^{+}$and lactate ions, which overflow from the cells due to exercise, can be buffered by $\mathrm{HCO}_{3}{ }^{-}$. Thus, the acid-buffering capacity of the muscles is improved while the increase of $\mathrm{H}^{+}$in muscles is reduced to delay muscular fatigue.

A meta-analysis summarizing 29 studies found that supplementation of $\mathrm{HCO}_{3}{ }^{-}$can improve anaerobic exercise capacity, significantly extending the time of exercise to exhaustion [38]. Studies also suggest that the greater the $\mathrm{pH}$ drop during exercise, the more beneficial the supplementation of $\mathrm{HCO}_{3}{ }^{-}[34,39]$. Some studies have compared the effects of acute and chronic $\mathrm{HCO}_{3}{ }^{-}$supplementation on anaerobic ability, with results suggesting that chronic supplementation is more effective at increasing anaerobic exercise capacity than acute supplementation. A potential problem with $\mathrm{HCO}_{3}{ }^{-}$supplementation is that an inappropriate dosage may result in acute gastrointestinal reactions, with symptoms that include nausea, stomach pain, diarrhea, and vomiting, all of which may negatively impact exercise performance [40]. Dose-response studies assessing commonly used 
$\mathrm{HCO}_{3}{ }^{-}$doses, typically ranging from $0.1-0.5 \mathrm{~g} / \mathrm{kg}$ body mass (BM), found that the most commonly used dose was $0.3 \mathrm{~g} / \mathrm{kg}$ BM [38, 40-43]. Studies have also shown that chronic supplementation at doses lower than $0.3 \mathrm{~g} /$ $\mathrm{kg} \mathrm{BM}$ results in better gastrointestinal tolerance than one-time acute and larger $\mathrm{HCO}_{3}{ }^{-}$supplementation dose before exercise [44-46].

Current studies have assessed the effects of $\mathrm{HCO}_{3}{ }^{-}$ supplementation on HIIT exercise performance, but few studies have assessed the independent effects of HIIT and $\mathrm{HCO}_{3}{ }^{-}$on anaerobic performance. There are several studies that have also assessed the impact of HIIT with $\mathrm{HCO}_{3}{ }^{-}$supplementation on aerobic performance [4749]. The studies of Jourkesh et al. (2011) [47] and Edge et al. (2004) [49] found that $\mathrm{HCO}_{3}{ }^{-}$supplementation with HIIT positively affects aerobic capacity. In contrast, a study by Driller et al. (2013) found that this combination had the opposite effect, although the researchers hypothesized that the finding may have been due to the unique subject characteristics (highly trained members on national teams), whose aerobic performance was sufficiently well-developed that it would not likely be impacted through the addition of supplemental $\mathrm{HCO}_{3}{ }^{-}$ $[48,50,51]$. Because of this finding, we chose healthy college students as our subjects instead of highly trained athletes, to enable a better understanding of the possible impact of $\mathrm{HCO}_{3}{ }^{-}$ingestion when coupled with HIIT.

The results of past studies led us to develop a research project that would assess the combination of chronic $\mathrm{HCO}_{3}{ }^{-}$supplementation with HIIT training, to explore whether this intervention can effectively improve anaerobic capacity in healthy young men. We hypothesized that the combination of chronic $\mathrm{HCO}_{3}{ }^{-}$supplementation during HIIT will result in an improvement of anaerobic exercise performance in this population.

\section{Methods}

\section{Subjects}

Healthy college-age male participants $(N=20 ; \bar{x}$ age $=$ $20.45 \pm 0.94$ yr.; $\bar{x}$ height $=1.76 \pm 0.05 \mathrm{~m} ; \bar{x}$ body mass $=$ $70.55 \pm 5.65 \mathrm{~kg} ; \bar{x} \quad \mathrm{BMI}=22.70 \pm 1.60 \mathrm{~kg} / \mathrm{m}[2], \bar{x}$ lean mass $\%=54.6 \pm 2.05, \bar{x}$ body fat $\%=15.96 \pm 4.03)$ constituted the subject pool (See Table 1). The inclusion criteria were as follows: 1) 18-24 year-old males; 2) BMI was between $18.5-23 \mathrm{~kg} / \mathrm{m}^{2}$; 3) Healthy, with no hypertension, diabetes or cardiovascular risk factors, and no other diagnosed diseases; 4) Subjects had no professional training during the 6-month period prior to the onset of this experimental protocol; 5) Subjects voluntarily agreed to participate in the experiment. Approval for the study was obtained from the Institutional Review Board of Beijing Sport University (BSU IRB). Informed consent was obtained from all participants. In addition, participants were required to avoid other training protocols and supplementation during the experiment, and were asked to maintain their typical diet and activities.

\section{Study design}

The research proposal was approved by the Institutional Review Board of Beijing Sport University. All subjects were fully informed about the purposes, procedures, and potential risks of this study. Subjects signed an informed consent and completed a health history questionnaire and physical activity questionnaire at the first visit, followed by an assessment of body composition. After these steps, they performed a graded exercise testing (GXT) on a cycle ergometer to evaluate maximal aerobic power output (MAP). This MAP value was considered the subject's basic exercise capacity for development of the individualized training plan. Subjects were randomly assigned to $\mathrm{HCO}_{3}{ }^{-}$(SB) and Placebo (PL) groups (see Table 1) to enhance the possibility of group equivalence. We found no significant differences in BMI, lean mass\%, body fat\% and MAP between the two groups. All subjects completed 6 weeks of HIIT (3 days per week) on a cycle ergometer. The intensity of the training was set to a higher level in the second three week assessment/ training period. Throughout this 6 -week training period, the $\mathrm{SB}$ group ingested a fluid containing $\mathrm{HCO}_{3}{ }^{-}$on every training day, while the placebo group ingested a similar beverage containing no $\mathrm{HCO}_{3}{ }^{-}$. Blood samples were taken before and after the first training, the third training in the third week, and the final training to measure serum $\mathrm{HCO}_{3}{ }^{-}$. A $30 \mathrm{~s}$ Wingate Anaerobic $30 \mathrm{~s}$ Cycling Test (WAnT) was conducted pre-, mid-, and post-intervention (i.e., before both HIIT and $\mathrm{HCO}_{3}{ }^{-}$interventions, after three weeks of interventions, and after six weeks of interventions respectively). During the WAnT, peak power, mean power, fatigue index, blood lactate, and heart rate were recorded. Subjects were asked to keep their normal schedule on the day before all interventions, and to avoid consuming, within $2 \mathrm{~h}$ before the test, carbonated drinks, alcohol, caffeine or other substances that could affect the GXT, WAnT and

Table 1 Subjects characteristics for two groups*

\begin{tabular}{llllllll}
\hline Group & Age $(\mathrm{yr})$ & Height $(\mathrm{cm})$ & Weight $(\mathrm{kg})$ & BMl $\left(\mathrm{kg} / \mathrm{m}^{2}\right)$ & Lean Mass $(\%)$ & Body Fat $(\%)$ & MAP $(\mathrm{W})$ \\
\hline SB & $20.35 \pm 0.44$ & $1.77 \pm 0.05$ & $71.52 \pm 5.20$ & $22.83 \pm 1.65$ & $46.05 \pm 2.20$ & $16.95 \pm 4.21$ & $183.55 \pm 35.65$ \\
PL & $20.51 \pm 0.21$ & $1.76 \pm 0.05$ & $69.57 \pm 6.18$ & $22.51 \pm 1.64$ & $45.15 \pm 1.90$ & $14.98 \pm 3.80$ & $179.67 \pm 25.97$ \\
\hline
\end{tabular}

Values are means $\pm \mathrm{SD}$. $\mathrm{SB}=\mathrm{HCO}_{3}{ }^{-}$group, $P L=$ placebo group

*There was not significant difference between two groups on these values 
blood test results. Subjects were also asked to avoid any strenuous exercise before GXT, WAnT, and blood test. All sports training, GXT, and WAnT were performed using a cycle ergometer. During the interventions, subjects were also asked to avoid any other professional training regimen and nutrition supplementation. Daily food consumption was recorded by subjects as a means of monitoring nutritional intake.

\section{Graded exercise testing}

The first segment of the exercise capacity test was GXT on a cycle ergometer (starting at $40 \mathrm{~W}+20 \mathrm{~W} \cdot 2 \mathrm{~min}^{-1}$ ), which was the basis for all the following steps. The maximal aerobic power output was identified as the highest workload that subjects can maintain during the entire test. Below are the equations for MAP.

If subjects completed $2 \mathrm{~min}$ of their last stage: $\mathrm{MAP}=$ $\mathrm{W}_{\text {final. }}$.

Where, MAP is the maximal aerobic power output, $\mathrm{W}_{\text {final }}$ is the power output (in watts) of the last complete stage that subjects performed.

If subjects did not complete $2 \mathrm{~min}$ of their last stage: $\mathrm{MAP}=\mathrm{W}_{\text {final }}+(\mathrm{t} / 120 \times 20)$.

Where, MAP is the maximal aerobic power output, $\mathrm{W}_{\text {final }}$ is the power output (in watts) of the last complete stage that subjects performed, and ' $t$ ' is the duration (i.e., time) that subjects performed in the uncompleted stage [52]. Polar monitors were worn by subjects to monitor heart rate. The standards for exhaustion included: 1) Heart rate reached $180 \mathrm{bpm} / \mathrm{min}$; 2) Subjects subjectively felt tired; 3) Subjects couldn't pedal at a constant load for more than $15 \mathrm{~s}$. Subjects were considered exhausted when they simultaneously met any two of the above criteria.

\section{HIIT intervention}

Both groups performed 6 weeks of the same HIIT training, the intensity of which was set based on MAP. This study set the first 3-week period and the second 3-week period as two distinct training stages with different training intensities, following the standard of prior research [53]. During the first 3 -week period the goal was for subjects to finish 4 sets of training during training days, with a 1-min interval between each set. Every set consisted of 1 min cycling, which included $30 \mathrm{~s}$ cycling at an intensity of $100 \%$ MAP and $30 \mathrm{~s}$ at $70 \%$ MAP. The second set intensity was changed to $40 \mathrm{~s}$ cycling at $100 \%$ MAP, plus $20 \mathrm{~s}$ cycling at $70 \%$ MAP. Training was performed by subjects three times per week, with the training sessions separated by at least one rest day. Prior to the training, subjects were required to do a warm-up at $60 \mathrm{~W}$ for $5 \mathrm{~min}$.

\section{$\mathrm{HCO}_{3}{ }^{-}$supplementation}

The $\mathrm{HCO}_{3}{ }^{-}$supplementation dose for $\mathrm{SB}$ was $0.2 \mathrm{~g} / \mathrm{kg}$ $\mathrm{BM} . \mathrm{HCO}_{3}{ }^{-}$was dissolved into $1 \mathrm{~L}$ drinking water with $15 \mathrm{~g}$ xylitol and $2 \mathrm{~g}$ orange flavoring to enhance the acceptability of the fluid. With the goal of lowering the potential for gastrointestinal distress, which could occur by drinking a high fluid volume too quickly, subjects were asked to consume the beverage over several opportunities during the 60-90 min before training. The beverage for PL was similar to that consumed by SB, except for containing no $\mathrm{HCO}_{3}{ }^{-}$.

\section{Wingate Anaerobic 30 s Cycling Test}

Subjects performed a Wingate Anaerobic $30 \mathrm{~s}$ Cycling Test with a Monark 894E (Model: Ergomedic 894E, Manufacturer: Healthcare International) at pre-, mid- and post-intervention. A 1-day (24h) interval was required between the test and the training. Subjects were instructed to take these three tests at the same time of the day. Subjects were given a 5-min standard warm-up prior to WAnT [54], including two 3-5 min all-out sprints and a constant warm-up at $1 \mathrm{~W} / \mathrm{kg}$ BM. Following a 5-min warm-up, WAnT was conducted according to the standard method of Bar-Or [55]. Peak power (PP), mean power (MP) and fatigue index (PD\%) of the test were calculated via Monark Anaerobic Testing software (Version: 3.3.0.0, Developed in Co-operation with HUR Labs). Heat rate was monitored by the Polar Rs800cx chest-worn heart rate monitor (Manufacturer: Polar Electro Oy) from the resting state to the recovery period for analyzing the heart rate recovery rate (HRR\%). The equation for HRR\%:

$$
\mathrm{HRR}_{10} \%=\left(\mathrm{HR}_{\max }-\mathrm{HR}_{10}\right) /\left(\mathrm{HR}_{\max }-\mathrm{HR}_{\text {rest }}\right) \times 100 \%
$$

Where $\mathrm{HRR}_{10} \%$ is the rate of heart rate recovery, $\mathrm{HR}_{\text {max }}$ is the maximum heart rate immediately after exercise, $H_{10}$ is the heart rate after $10 \mathrm{~min}$ of exercise, and $H R_{\text {rest }}$ is the resting heart rate.

\section{Lactate test}

Finger blood samples $(10 \mu \mathrm{l})$ were obtained while in a non-exercise state as follows: immediately, $3 \mathrm{~min}, 5 \mathrm{~min}$, $7 \mathrm{~min}$, and $10 \mathrm{~min}$ after exercise following all three WAnT. The samples were tested via a glucose and lactate analyzer (Biosen C-Line, EKF Diagnostics), and the lactate clearance rate was predicted as follows:

$$
\mathrm{LA}_{10} \%=\left(\mathrm{LA}_{\max }-\mathrm{LA}_{10}\right) /\left(\mathrm{LA}_{\max }-\mathrm{LA}_{\text {rest }}\right) \times 100 \%
$$

Where $\mathrm{LA}_{10} \%$ is the lactic acid clearance rate at 10 min after exercise, $\mathrm{LA}_{\max }$ is the peak lactate value after exercise, $\mathrm{LA}_{10}$ is the lactic acid value at $10 \mathrm{~min}$ after exercise, and $\mathrm{LA}_{\text {rest }}$ is the value of lactic acid before exercise.

Lactate clearance velocity was predicted as follows: 


$$
\mathrm{V}_{10}=\left(\mathrm{LA}_{\max }-\mathrm{LA}_{10}\right) / \times(10-\mathrm{t})
$$

Where $\mathrm{V}_{10}$ is the lactate clearance velocity at $10 \mathrm{~min}$ after exercise, $\mathrm{LA}_{\max }$ is the peak lactate value after exercise, $\mathrm{LA}_{10}$ is the lactic acid value at $10 \mathrm{~min}$ after exercise, and $t$ is the time when peak lactate value appears.

\section{Serum $\mathrm{HCO}_{3}{ }^{-}$test}

Venous blood samples of $2 \mathrm{ml}$ were collected before and $30 \mathrm{~min}$ after the first training, the third training in the third week, and the last training to measure the serum $\mathrm{HCO}_{3}{ }^{-}$by a Mindary BS- 420 automatic biochemical analyzer.

\section{Statistical analyses}

Data were entered into Microsoft Excel 2010 and analyzed using SPSS version 22.0. Two-way repeated measures ANOVA was performed on the three tests to assess the interaction between time (before intervention, during intervention, after intervention) and the cohort (SB and PL). Simple effect analysis was performed for the horizontal comparison of between-group-factors when there was an interaction, and longitudinal comparison of within-group-factors was performed when there was no interaction. Otherwise, one-way repeated measures ANOVA and independent samples t-tests were used to respectively compare both intra- and inter-group factors, or only one of these two factors based on the main influencing effects. Statistical significance was set at $p<0.05$.

\section{Results}

All subjects completed 6 weeks of intervention, with no subject dropouts.

\section{Subjects characteristics}

There were no significant differences of measured factors between SB and PL $(p>0.05)$. (see Table 1$)$.

\section{$\mathrm{HCO}_{3}{ }^{-}$level analysis}

The alkaline reserve in SB was improved following supplementation (see Table 2). The results of all three tests showed that the serum $\mathrm{HCO}_{3}{ }^{-}$of $\mathrm{SB}$ was significantly higher $(p<0.05)$ than that of PL both before and after training. Moreover, compared to the pre-intervention, serum $\mathrm{HCO}_{3}{ }^{-}$both before and after HIIT were significantly increased $(p<0.01)$ in mid-intervention. Compared to the mid-intervention, serum $\mathrm{HCO}_{3}{ }^{-}$both before and after HIIT were significantly increased $(p<$ $0.05)$ at post-intervention in SB, while the PL showed no significant changes.

\section{Wingate Anaerobic 30 s Cycling Test}

The relative PP of SB was significantly higher in both the first three week period and the second three week period $(p<0.01)$. However, in PL a significant increase was only found in the first three week period $(\mathrm{p}<0.05)$ (see Fig. 1). There was also a significant difference $(p<0.01)$ in PP between SB and PL after six weeks of training, with the SB having higher PP. Although the relative MP in both groups improved significantly $(p<0.01)$ after only three weeks, no significant difference was found between groups. PD\% was also not different between groups. However, SB experienced a significant decrease in PD\% from pre-intervention to mid-intervention $(p<0.05)$, and from mid-intervention to the post-intervention $(\mathrm{p}<0.01)$. PL experienced a significant decrease of $\mathrm{PD} \%$ after six weeks of intervention $(P<0.05)$ (see Table 3$)$.

\section{Blood lactate}

In the three WAnT tests, there was no difference in the resting LA, either between or within groups. $\mathrm{LA}_{\max }$ in SB increased significantly after three weeks of intervention $(p<0.01)$, while PL experienced no significant difference after six weeks. $\mathrm{V}_{10}$ and $\mathrm{LA}_{10} \%$ were significantly different between groups after six weeks of intervention $(p<0.01)$ (see Fig. 2).

\section{Heart rate}

Though no significant difference of $\mathrm{HRR}_{10} \%$ was found between SB and PL during six weeks, only the SB group improved significantly from the mid-intervention to post-intervention $(p<0.05)$ (see Table 3).

\section{Discussion}

The purpose of this study was to investigate whether $\mathrm{HCO}_{3}{ }^{-}$supplementation during 6 weeks of HIIT results in a greater improvement in anaerobic capacity in

Table 2 Serum $\mathrm{HCO}_{3}{ }^{-}$level before and after HIIT in the pre-, mid- and post-intervention

\begin{tabular}{|c|c|c|c|c|c|c|}
\hline \multirow[t]{2}{*}{ Group } & \multicolumn{2}{|c|}{ Pre-intervention } & \multicolumn{2}{|l|}{ Mid-intervention } & \multicolumn{2}{|l|}{ Post-intervention } \\
\hline & Before HIIT & After HIIT & Before HIIT & After HIIT & Before HIIT & After HIIT \\
\hline$\overline{\mathrm{SB}}$ & $25.00 \pm 1.06^{\dagger}$ & $23.62 \pm 1.07^{\dagger}$ & $27.74 \pm 1.04^{t^{* *}}$ & $25.72 \pm 0.83^{t^{* *}}$ & $28.49 \pm 0.87^{f^{* * \Delta}}$ & $26.15 \pm 0.73^{1 * * \Delta}$ \\
\hline$P L$ & $21.63 \pm 0.98$ & $20.30 \pm 0.58$ & $21.31 \pm 1.16$ & $19.99 \pm 0.99$ & $21.48 \pm 1.18$ & $20.55 \pm 1.24$ \\
\hline
\end{tabular}

Values are means $\pm \mathrm{SD}$. $\mathrm{SB}=\mathrm{HCO}_{3}{ }^{-}$group, $\mathrm{PL}=$ placebo group

${ }^{* *}$ indicates a significant difference vs. pre-intervention $(p<0.05)$

${ }^{\Delta}$ indicates a significant difference from mid- to post-intervention $(p<0.05)$

${ }^{\dagger}$ indicates a significant difference $(p<0.05)$ vs. PL-group 


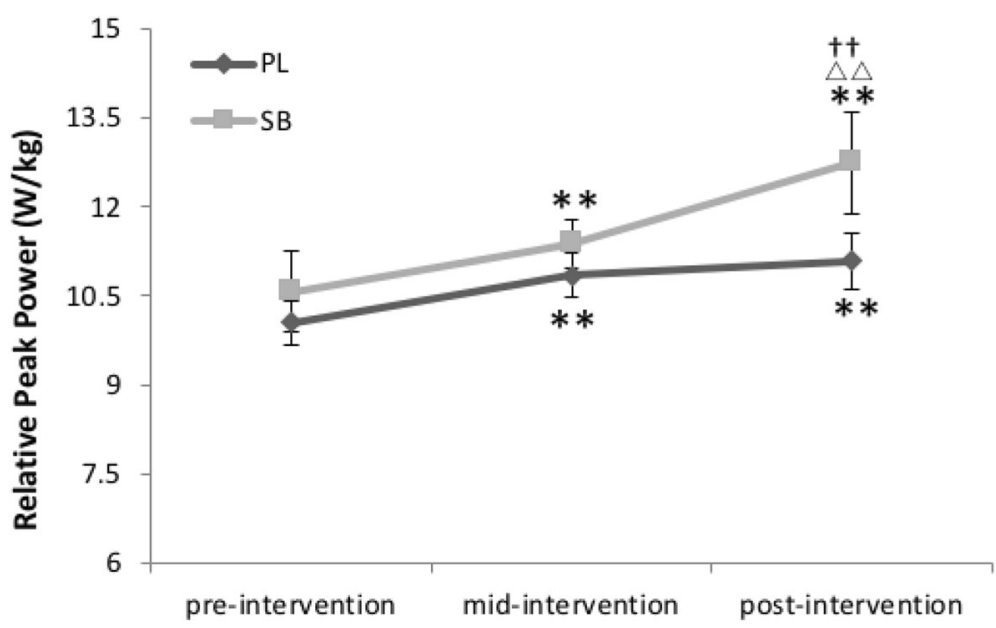

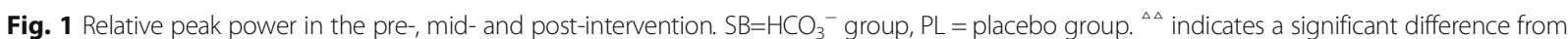
mid- to post-intervention $(p<0.01) .{ }^{*}$ indicates a significant difference from pre- to mid-interventin or from pre- to post-intervention $(p<0.01)$. $†+$ indicates a significant difference $(p<0.01)$ vs. PL-group

healthy young men than HIIT alone. We hypothesized that chronic supplementation of $\mathrm{HCO}_{3}{ }^{-}$would be in synergy with HIIT training to improve the subjects' alkaline reserve and increase the acid-buffering capacity during exercise. We believed that this combination could postpone muscular fatigue and improve the body's capacity to provide ATP and enhance HIIT's effect on anaerobic performance. Our results support this hypothesis. The findings demonstrated that serum $\mathrm{HCO}_{3}{ }^{-}$was significantly different between groups in all

Table 3 WAnT related indexes data in the pre-, mid- and post-intervention

\begin{tabular}{|c|c|c|c|c|}
\hline Variable & Group & Pre-intervention & Mid-intervention & Post-intervention \\
\hline \multirow[t]{2}{*}{ Relative peak power (W/kg) } & SB & $10.58 \pm 0.69$ & $11.38 \pm 0.40^{* *}$ & $12.78 \pm 0.68^{* * \Delta \Delta \dagger \dagger}$ \\
\hline & $P L$ & $10.05 \pm 0.38$ & $10.85 \pm 0.37^{* *}$ & $11.09 \pm 0.47^{* *}$ \\
\hline \multirow[t]{2}{*}{ Relative mean power (W/kg) } & SB & $7.53 \pm 0.59$ & $8.72 \pm 0.43^{* *}$ & $9.17 \pm 0.40^{* *}$ \\
\hline & $P L$ & $6.96 \pm 0.21$ & $7.77 \pm 0.59^{* *}$ & $8.25 \pm 0.74^{* *}$ \\
\hline \multirow[t]{2}{*}{ Fatigue index \% } & SB & $55.78 \pm 9.24$ & $48.95 \pm 6.81^{*}$ & $44.06 \pm 6.71^{* *}$ \\
\hline & $P L$ & $60.57 \pm 12.50$ & $55.89 \pm 12.11$ & $53.10 \pm 10.66^{*}$ \\
\hline \multirow[t]{2}{*}{ Resting LA (mmol/L) } & SB & $1.92 \pm 0.64$ & $2.00 \pm 1.03$ & $1.89 \pm 0.55$ \\
\hline & $P L$ & $2.09 \pm 0.65$ & $2.17 \pm 0.74$ & $1.59 \pm 0.58$ \\
\hline \multirow[t]{2}{*}{ LAmax (mmol/L) } & SB & $13.85 \pm 1.40$ & $15.71 \pm 1.25$ & $16.44 \pm 1.06^{* *}$ \\
\hline & $P L$ & $14.83 \pm 2.49$ & $14.69 \pm 2.10$ & $14.62 \pm 2.06$ \\
\hline \multirow[t]{2}{*}{ LA after (10 min) WAnT (mmol/L) } & SB & $12.39 \pm 2.14$ & $13.43 \pm 1.24$ & $13.02 \pm 1.65$ \\
\hline & $P L$ & $13.52 \pm 2.42$ & $12.78 \pm 1.72$ & $12.45 \pm 1.68$ \\
\hline \multirow[t]{2}{*}{$V_{10}\left(\mathrm{mmol} \cdot \mathrm{L}^{-1} \cdot \mathrm{min}^{-1}\right)$} & SB & $0.24 \pm 0.08$ & $0.49 \pm 0.12^{* *}$ & $0.62 \pm 0.10^{* * \Delta t \dagger}$ \\
\hline & $P L$ & $0.23 \pm 0.07$ & $0.39 \pm 0.13^{*}$ & $0.43 \pm 0.12^{* *}$ \\
\hline \multirow[t]{2}{*}{$\mathrm{LA}_{10} \%$} & SB & $11.58 \pm 1.41$ & $16.16 \pm 3.01^{* *}$ & $20.40 \pm 1.81^{* * \Delta \Delta \dagger}$ \\
\hline & $P L$ & $10.59 \pm 2.72$ & $14.36 \pm 2.26^{* *}$ & $16.00 \pm 2.07^{* *}$ \\
\hline \multirow[t]{2}{*}{$\mathrm{HRR}_{10} \%$} & SB & $65.38 \pm 5.32$ & $75.07 \pm 10.20^{*}$ & $80.54 \pm 4.98^{* * \Delta}$ \\
\hline & $P L$ & $63.5 \pm 9.35$ & $68.39 \pm 8.77^{*}$ & $73.33 \pm 8.19^{*}$ \\
\hline
\end{tabular}

Values are means $\pm \mathrm{SD}$. $L A=$ lactic acid, $L A m a x=$ maximal lactic acid, $W A n T=$ Wingate anaerobic test, $S B=\mathrm{HCO}_{3}{ }^{-} \mathrm{group} P L=$ placebo group. $(p<0.05)$

${ }^{\Delta}$ indicates a significant difference from mid- to post-intervention $(p<0.05)$

${ }^{\Delta}$ indicates a significant difference from mid- to post-intervention $(p<0.01)$

*indicates a significant difference from pre- to mid-intervention or from pre- to post-intervention $(p<0.05)$

${ }^{*}$ indicates a significant difference from pre- to mid-intervention or from pre- to post-intervention $(p<0.01)$

${ }^{+{ }^{+}}$indicates a significant difference $(p<0.01)$ vs. PL-group 

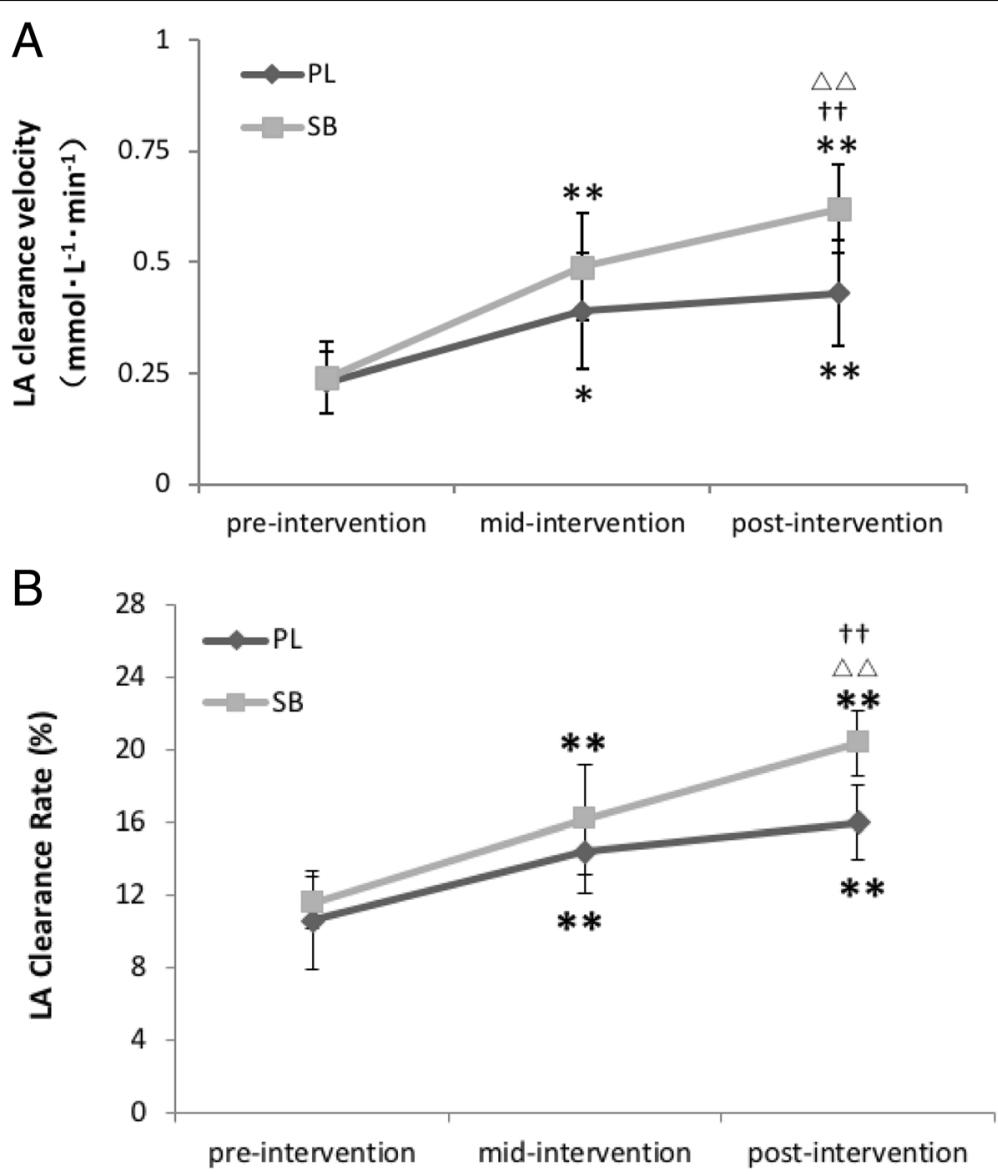

Fig. $\mathbf{2}$ a, b $L A$ clearance velocity and $L A$ clearance rate (\%) in the pre-, mid- and post-intervention. $S B=\mathrm{HCO}_{3}{ }^{-}$group, $P L=$ placebo group

tests $(p<0.05)$. In addition, serum $\mathrm{HCO}_{3}{ }^{-}$of the SB increased significantly after each stage of intervention (from pre-intervention to mid-intervention, $p<0.01$; from mid-intervention to post-intervention, $p<0.05$ ), suggesting that the alkaline reserve of subjects in SB increased after $\mathrm{HCO}_{3}{ }^{-}$supplementation. These results correspond to the results of several other studies [44, 48]. According to the test results of WAnT, the significant positive changes were more evident in SB rather than in PL, which is likely due to the chronic $\mathrm{HCO}_{3}{ }^{-}$ supplementation intervention.

During our 6-week experiment, only one subject experienced problematic gastrointestinal effects after taking $\mathrm{HCO}_{3}{ }^{-}$supplements. Through our inquiry and observation, and the fact that this was limited to a single subject, we believe that this may have been the result of a preexisting GI condition. Another possibility is that the drinking speed of the supplement was excessively fast, creating an increased gastrointestinal burden. As mentioned earlier, studies assessing $\mathrm{HCO}_{3}{ }^{-}$supplementation have most commonly used $\mathrm{HCO}_{3}^{-}$at a concentration is $0.3 \mathrm{~g} / \mathrm{kg} \mathrm{BM}$ [38, 40-43]. It has been found that longer-term supplementation at this and lower dosage levels result in improved gastrointestinal tolerance [44-46]. The dosage applied in this study was $0.2 \mathrm{~g} / \mathrm{kg} \mathrm{BM}$, which, according to the study by Bishop et al. (2005), could effectively elevate the blood $\mathrm{HCO}_{3}{ }^{-}$level without causing negative gastrointestinal reactions [56].

According to the analyzed data, after 6 weeks of intervention relative mean power $(p<0.05)$, relative peak power $(p<0.05)$, and fatigue index $(p<0.01)$ of PL all significantly improved, implying that the effect of HIIT training alone significantly improves anaerobic capacity. This finding is consistent with earlier studies [13, 14, 57]. In the study of Naimo et al. (2015) [14], 4 weeks of HIIT training significantly increased the peak power and mean power in WAnT of college hockey players. Astorino et al.(2012) [13] conducted a short-term HIIT training for 20 males and females who often engaged in physical activity and found that both relative PP and relative MP improved significantly. However, neither of these two studies found a significant improvement in the fatigue index [13]. It is possible that this may be due to the longer training period in these two studies than in the study we designed. Therefore, by imposing more intensive physiological stimuli through the training, the 
transport and clearance ability of lactic acid could be more obvious, the muscle acid resistance could be stronger and, ultimately, the onset of fatigue could be slower.

Although significant differences in relative MP and PD\% between groups were not observed in our study, there was a significant $(p<0.01)$ difference in relative PP over the six week intervention period. Hence, our data suggest that $\mathrm{HCO}_{3}{ }^{-}$supplementation aided in the improvement of anaerobic performance. In addition, some additional changes occurred in SB, including the significant increase of relative PP in the second three week intervention period, and a significant improvement of PD\% $(p<0.01)$ after six weeks. Neither of these changes was observed in PL. As a result of the mechanisms described previously, taking a sufficient dose of $\mathrm{HCO}_{3}{ }^{-}$before high intensity exercise can reduce the accumulation of acid in muscle cells, delay the generation of fatigue, and enhance skeletal muscle contraction [46]. It has been demonstrated that changes in the metabolism of skeletal muscles resulting from $\mathrm{HCO}_{3}{ }^{-}$ supplementation before exercise improve the function of anaerobic metabolism of skeletal muscles. This alteration is beneficial for high-intensity exercise [58]. Therefore, our data suggest that, in the population studied, supplementation of $\mathrm{HCO}_{3}{ }^{-}$during HIIT may have a positive impact of HIIT training on anaerobic capacity through multiple mechanisms.

The $30 \mathrm{~s}$ Wingate anaerobic test is heavily reliant on the ATP/CP and anaerobic glycolytic system. The peak lactate level after exercise represents the body's maximum tolerance to lactic acid. It also reflects the capacity of the glycolytic system to produce ATP. As can be seen in Table 3, there is a significant increase in peak lactate level only in SB over six weeks of intervention $(p<0.01)$. This result suggests that the ability of glycolytic system to produce ATP is enhanced with $\mathrm{HCO}_{3}{ }^{-}$supplementation. In addition, although lactic acid clearance velocity and clearance rate at $10 \mathrm{~min}$ after WAnT in PL improved, our findings indicate that the increase in SB is more evident on these values, resulting in a significant difference between SB and PL $(\mathrm{p}<0.01)$. Similar results have been demonstrated in earlier studies [34]. This suggests that the supplementation of $\mathrm{HCO}_{3}{ }^{-}$positively effects the clearance of lactate after exercise. The improvement in lactic acid clearance suggests that exogenous $\mathrm{HCO}_{3}{ }^{-}$supplementation can increase the intracellular alkali reserve, slow the $\mathrm{pH}$ reduction in muscles, and delay the onset of fatigue.

We initially speculated that $\mathrm{HCO}_{3}{ }^{-}$supplementation may promote lactic acid clearance after anaerobic exercise, reduce lactic acid accumulation and increase blood $\mathrm{pH}$, which could increase the partial pressure of oxygen $\left(\mathrm{PO}_{2}\right)$ in blood and accelerate heart rate recovery. The possible mechanism for this is that blood $\mathrm{pH}$ and partial pressure of carbon dioxide $\left(\mathrm{PCO}_{2}\right)$ are pertinent to the affinity of $\mathrm{Hb}$ with $\mathrm{O}_{2}$ and the $\mathrm{PO}_{2}$ in the blood [59]. Both elevated $\mathrm{pH}$ and decreased $\mathrm{PCO}_{2}$ can increase the affinity of $\mathrm{Hb}$ with $\mathrm{O}_{2}$ and increase blood $\mathrm{PO}_{2}$ [59]. It is known that heart rate recovery and $\mathrm{PO}_{2}$ are positively correlated, while hypoxia and cardiac autonomic nervous dysfunction are closely related [60]. We found, however, that the rate of heart rate recovery in both groups increased after six weeks of intervention, and there was no significant difference between groups in heart rate recovery $(p>0.05)$. This is consistent with the fact that we have not found any report demonstrating an improvement of the heart rate recovery after exercise following ingestion of $\mathrm{HCO}_{3}{ }^{-}$. Our data suggest that oral supplementation of $\mathrm{HCO}_{3}{ }^{-}$in a low dosage may positively affect heart rate recovery after exercise. While this may be the result of improved neurological regulation, there is no obvious cause of this finding.

The present study has several limitations, including no data on how to enhance the taste of supplements without affecting its efficacy. In addition, our study used a relatively small sample of only healthy young men, which limits the generalizability to women and other populations. Therefore, we would encourage a duplication of this study's protocol with other populations in future research.

\section{Conclusions}

Our data suggest that, in healthy young men, the combination of $\mathrm{HCO}_{3}{ }^{-}$supplementation and HIIT can enhance the effect of HIIT on anaerobic performance, including improving power output, delaying fatigue onset, and improving the blood lactate clearance rate and velocity after the anaerobic exercise.

\section{Abbreviations}

BM: Body mass; GXT: Graded exercise testing; $\mathrm{H}^{+}$: Hydrogen ion;

$\mathrm{H}_{2} \mathrm{CO}_{3}$ : Carbonic acid; $\mathrm{HCO}_{3}{ }^{-}$: Bicarbonate ion; $\mathrm{NaHCO}_{3}$ : Sodium bicarbonate; HIIT: High-intensity interval training; HRR\%: Heart rate recovery rate;

MAP: Maximal aerobic power; MP: Mean power; $\mathrm{Na}^{+}$: Sodium ion; $\mathrm{PCO}_{2}$ : Partial pressure of carbon dioxide; $\mathrm{PD} \%$ : Fatigue index; $\mathrm{PO}_{2}$ : Partial pressure of oxygen; PP: Peak power; WAnT: Wingate Anaerobic 30 s Cycling Test

\section{Acknowledgments}

Thank you to all the participants for participating in this study.

\section{Funding}

Funding was provided by the Fundamental Research Funds for the Central Universities.

\section{Availability of data and materials}

The datasets generated and/or analyzed as part of the current study are not publicly available due to confidentiality agreements with subjects. However, they can be made available solely for the purpose of review and not for the purpose of publication from the corresponding author upon reasonable request.

\section{Authors' contributions}

JW was responsible for data collection, data interpretation, writing and revision of the manuscript, under the direction and assistance of JQ and LY who assisted with each step and completion of the manuscript. ZH assisted in the data collection and data interpretation. DB assisted in the revision of 
the manuscript. WC assisted in the completion of the manuscript. The authors declare no conflict of interests with the current publication, and all authors approved the final version of the manuscript.

\section{Ethics approval and consent to participate}

The research proposal was approved by the Institutional Review Board of Beijing Sport University (BSU IRB) and all participants gave written informed consent prior to study participation.

\section{Consent for publication}

Not applicable, no individual person's data was presented.

\section{Competing interests}

The authors declare that they have no competing interests.

\section{Publisher's Note}

Springer Nature remains neutral with regard to jurisdictional claims in published maps and institutional affiliations.

\section{Author details}

${ }^{1}$ College of Kinesiology, Beijing Sport University, Beijing, BJ, China. ${ }^{2}$ Department of Nutrition, Georgia State University, Atlanta, GA, USA. ${ }^{3}$ Center for the Study of Human Health, Emory University, Atlanta, GA, USA.

\section{Received: 28 October 2018 Accepted: 28 March 2019}

\section{Published online: 15 April 2019}

\section{References}

1. Weston M, Taylor KL, Batterham AM, Hopkins WG. Effects of low-volume high-intensity interval training (HIT) on fitness in adults: A meta-analysis of controlled and non-controlled trials. Sports Med. 2014;44(7):1005-17.

2. Tabata I, Nishimura K, Kouzaki M, Hirai Y, Ogita F, Miyachi M, Yamamoto K. Effects of moderate-intensity endurance and high-intensity intermittent training on anaerobic capacity and VO2max. Med Sci Sports Exerc. 1996;28(10):1327-30.

3. Mcrae G, Payne A, Zelt JGE, Scribbans TD, Jung ME, Little JP, Gurd BJ. Extremely low volume, whole-body aerobic-resistance training improves aerobic fitness and muscular endurance in females. Appl Physiol Nutr Metab. 2012;37(6):1124

4. Metcalfe RS, Babraj JA, Fawkner SG, Vollaard NB. Towards the minimal amount of exercise for improving metabolic health: beneficial effects of reduced-exertion high-intensity interval training. Eur J Appl Physiol. 2012:112(7):2767-75.

5. Adamson S, Lorimer R, Cobley JN, Lloyd R, Babraj J. High intensity training improves health and physical function in middle aged adults. Biology. 2014;3(2):333-44.

6. Perry CG, Heigenhauser GJ, Bonen A, Spriet LL. High-intensity aerobic interval training increases fat and carbohydrate metabolic capacities in human skeletal muscle. Appl Physiol Nutr Metab. 2008;33(6):1112-23.

7. Burgomaster KA, Hughes SC, Heigenhauser GJ, Bradwell SN, Gibala MJ. Six sessions of sprint interval training increases muscle oxidative potential and cycle endurance capacity in humans. J Appl Physiol. 2005;98(6):1985-90.

8. Burgomaster KA, Heigenhauser GJ, Gibala MJ. Effect of short-term sprint interval training on human skeletal muscle carbohydrate metabolism during exercise and time-trial performance. J Appl Physiol. 2006;100(6):2041-7.

9. Gibala MJ, Little JP, Essen MV, Wilkin GP, Burgomaster KA, Safdar A, Raha S, Tarnopolsky MA. Short-term sprint interval versus traditional endurance training: similar initial adaptations in human skeletal muscle and exercise performance. J Physiol. 2010;575(3):901-11.

10. Jacobs RA, Flück D, Bonne TC, Bürgi S, Christensen PM, Toigo M, Lundby C. Improvements in exercise performance with high-intensity interval training coincide with an increase in skeletal muscle mitochondrial content and function. J Appl Physiol. 2013;115(6):785-93.

11. Hoshino D, Yoshida Y, Kitaoka Y, Hatta H, Bonen A. High-intensity interval training increases intrinsic rates of mitochondrial fatty acid oxidation in rat red and white skeletal muscle. Appl Physiol Nutr Metab. 2013;38(3):326-33

12. Little JP, Safdar A, Bishop D, Tarnopolsky MA, Gibala MJ. An acute bout of high-intensity interval training increases the nuclear abundance of PGC-1a and activates mitochondrial biogenesis in human skeletal muscle. Am J Physiol Regul Integr Comp Physiol. 2011;300(6):R1303.
13. Astorino TA, Allen RP, Roberson DW, Jurancich M. Effect of high-intensity interval training on cardiovascular function, VO2max, and muscular force. J Strength Cond Res. 2012;26(1):138.

14. Naimo MA, de Souza EO, Wilson JM, Carpenter AL, Gilchrist P, Lowery RP, Averbuch B, White TM, Joy J. High-intensity interval training has positive effects on performance in ice hockey players. Int J Sports Med. 2015;36(01):61-6.

15. Hoshino D, Kitaoka Y, Hatta H. High-intensity interval training enhances oxidative capacity and substrate availability in skeletal muscle. J Phys Fitness Sports Med. 2016;5(1):13-23

16. Buckley S, Knapp K, Lackie A, Lewry C, Horvey K, Benko C, Trinh J, Butcher S. Multimodal high-intensity interval training increases muscle function and metabolic performance in females. Appl Physiol Nutr Metab. 2015;40(11):1157-62

17. Gastin PB, Costill DL, Lawson DL, Krzeminski K, Mcconell GK. Accumulated oxygen deficit during supramaximal all-out and constant intensity exercise. Med Sci Sports Exerc. 1995;27(2):255.

18. Gastin PB, Lawson DL. Influence of training status on maximal accumulated oxygen deficit during all-out cycle exercise. Eur J Appl Physiol Occup Physiol. 1994;69(4):321-30

19. Gastin PB. Energy system interaction and relative contribution during maximal exercise. Sports Med. 2001;31(10):725.

20. Tomlin DL, Wenger $\mathrm{H}$. The relationship between aerobic fitness and recovery from high intensity intermittent exercise. Sports Med. 2001;31(1):1-11.

21. Thorstensson A, Sjödin B, Karlsson J. Enzyme activities and muscle strength after "sprint training" in man. Acta Physiol. 2010;94(3):313-8.

22. Macdougall JD, Hicks AL, Macdonald JR, Mckelvie RS, Green HJ, Smith KM. Muscle performance and enzymatic adaptations to sprint interval training. J Appl Physiol. 1998;84(6):2138-42.

23. Simoneau JA, Lortie G, Boulay MR, Marcotte M, Thibault MC, Bouchard C. Effects of two high-intensity intermittent training programs interspaced by detraining on human skeletal muscle and performance. Eur J Appl Physiol Occup Physiol. 1987;56(5):516-21.

24. Péronnet F, Meyer T, Aguilaniu B, Juneau CE, Faude O, Kindermann W. Bicarbonate infusion and $\mathrm{pH}$ clamp moderately reduce hyperventilation during ramp exercise in humans. J Appl Physiol. 2007;102(1):426-8.

25. Clamann HP, Broecker KT. Relation between force and fatigability of red and pale skeletal muscles in man. Am J Phys Med. 1979;58(2):70-85.

26. Kemp G. Muscle cell volume and $\mathrm{pH}$ changes due to glycolytic ATP synthesis. J Physiol. 2007;582(1):461-5.

27. Jackson DC. Ion regulation in exercise: lessons from comparative physiology. Biochem Exerc. 1990;7:375-86.

28. Greenleaf JE, Brock PJ. Na+ and Ca2+ ingestion: plasma volume-electrolyte distribution at rest and exercise. J Appl Physiol Respir Environ Exerc Physiol. 1980;48(48):838-47.

29. Lindh AM, Peyrebrune MC, Ingham SA, Bailey DM, Folland JP. Sodium bicarbonate improves swimming performance. Int J Sports Med. 2007;29(06):519-23.

30. Mcnaughton LR, Siegler J, Midgley A. Ergogenic effects of sodium bicarbonate. Curr Sports Med Rep. 2008;7(4):230-6.

31. Wilkes D, Gledhill N, Smyth R. Effect of acute induced metabolic alkalosis on 800-m racing time. Med Sci Sports Exerc. 1983;15(4):277-80.

32. Goldfinch J, Naughton LM, Davies P. Induced metabolic alkalosis and its effects on 400-m racing time. Eur J Appl Physiol Occup Physiol. 1988;57(1):45-8.

33. Horswill CA, Costill DL, Fink WJ, Flynn MG, Kirwan JP, Mitchell JB, Houmard JA. Influence of sodium bicarbonate on sprint performance: relationship to dosage. Med Sci Sports Exerc. 1988;20(6):566-569.

34. Mc Naughton L, Thompson D. Acute versus chronic sodium bicarbonate ingestion and anaerobic work and power output. J Sports Med Phys Fitness. 2001;41(4):456-62.

35. Mueller SM, Gehrig SM, Frese S, Wagner CA, Boutellier U, Toigo M. Multiday acute sodium bicarbonate intake improves endurance capacity and reduces acidosis in men. J Int Soc Sports Nutr. 2013;10(1):16.

36. Price MJ, Singh M. Time course of blood bicarbonate and $\mathrm{pH}$ three hours after sodium bicarbonate ingestion. Int J Sports Physiol Perform. 2008;3(2):240-2.

37. Roth DA. The sarcolemmal lactate transporter: transmembrane determinants of lactate flux. Med Sci Sports Exerc. 1991;23(8):925.

38. Matson $L G$, Tran ZV. Effects of sodium bicarbonate ingestion on anaerobic performance: a meta-analytic review. Int J Sport Nutr. 1993;3(1):2-28.

39. Driller MW, Gregory JR, Williams AD, Fell JW. The effects of serial and acute NaHCO3 loading in well-trained cyclists. J Strength Cond Res. 2012;26(10):2791. 
40. Burke LM, Pyne DB. Bicarbonate loading to enhance training and competitive performance. Int J Sports Physiol Perform. 2007;2(1):93.

41. Applegate E. Effective nutritional ergogenic aids. Int J Sport Nutr. 1999;9(2):229-39.

42. McNaughton LR, Dalton B, Tarr J, Buck D. Neutralize acid to enhance performance. Sportscience Training \& Technology. http://www.sportsci.org/ traintech/buffer/lrm.htm.

43. Higgins MF, James RS, Price MJ. The effects of sodium bicarbonate (NaHCO3) ingestion on high intensity cycling capacity. J Sports Sci. 2013;31(9):972-81.

44. Edge J, Bishop D, Goodman C. Effects of chronic NaHCO3 ingestion during interval training on changes to muscle buffer capacity, metabolism, and short-term endurance performance. J Appl Physiol. 2006;101(3):918-25.

45. Douroudos II, Fatouros IG, Gourgoulis V, et al. Dose-related effects of prolonged $\mathrm{NaHCO} 3$ ingestion during high-intensity exercise. Med Sci Sports Exerc. 2006;38(10):1746-53.

46. Shelton J, Kumar GVP. Sodium bicarbonate - a potent ergogenic aid? Food Nutr Sci. 2010;1(1):1-4.

47. Jourkesh M, Ahmaidi S, Keikha BM, Sadri I, Ojagi A. Effects of six weeks sodium bicarbonate supplementation and high-intensity interval training on endurance performance and body composition. Ann Biol Res. 2011:2:403-13.

48. Driller MW, Gregory JR, Williams AD, Fell JW. The effects of chronic sodium bicarbonate ingestion and interval training in highly trained rowers. Int J Sport Nutr Exerc Metab. 2013;23(1):40-7.

49. Edge J, Bishop D, Goodman C. Chronic sodium bicarbonate ingestion affects training adaptations during severe exercise training. Med Sci Sports Exerc. 2004;36(36):S201.

50. Cameron SL, Gray AR, Fairbairn KA. Increased blood pH but not performance with sodium bicarbonate supplementation in elite Rugby union players. Int J Sport Nutr Exerc Metab. 2010;20(4):307-21.

51. Zabala M, Peinado AB, Calderón FJ, Sampedro J, Castillo MJ, Benito PJ. Bicarbonate ingestion has no ergogenic effect on consecutive all out sprint tests in BMX elite cyclists. Eur J Appl Physiol. 2011;111(12):3127-34.

52. Dantas JL, Pereira G, Nakamura FY. Five-kilometers time trial: preliminary validation of a short test for cycling performance evaluation. Asian J Sports Med. 2015;6(3):e23802.

53. Baker D. Recent trends in high-intensity aerobic training for field sports. Professional Strength \& Conditioning; 2011.

54. Ziemann E, Grzywacz T, Łuszczyk M, Laskowski R, Olek RA, Gibson AL. Aerobic and anaerobic changes with high-intensity interval training in active college-aged men. J Strength Cond Res. 2011;25(4):1104.

55. Bar-Or O. The Wingate anaerobic test an update on methodology, reliability and validity. Sports Med. 1987:4(6):381-94.

56. D B BC. Effects of induced metabolic alkalosis on prolonged intermittentsprint performance. Med Sci sports Exerc. 2005;37(5):759-67.

57. Foster C, Farland CV, Guidotti F, et al. The effects of high intensity interval training vs steady state training on aerobic and anaerobic capacity. J Sports Sci Med. 2015;14(4):747.

58. Requena B, Zabala M, Padial P, Feriche B. Sodium bicarbonate and sodium citrate: ergogenic aids? J Strength Cond Res. 2005;19(1):213.

59. Collins J, A R, J G, L H, O'Driscoll R. Relating oxygen partial pressure, saturation and content: the haemoglobin-oxygen dissociation curve. Breathe. 2015;11(3):194-201.

60. Crisafulli E, Vigna M, lelpo A, et al. Heart rate recovery is associated with ventilatory constraints and excess ventilation during exercise in patients with chronic obstructive pulmonary disease. Eur J Prev Cardiol. 2018;25(15):1667-74.

Ready to submit your research? Choose BMC and benefit from:

- fast, convenient online submission

- thorough peer review by experienced researchers in your field

- rapid publication on acceptance

- support for research data, including large and complex data types

- gold Open Access which fosters wider collaboration and increased citations

- maximum visibility for your research: over $100 \mathrm{M}$ website views per year

At BMC, research is always in progress.

Learn more biomedcentral.com/submissions 